\title{
Genome-wide transcriptome profiling of Gossypium spp. roots during early growth after infection with Rotylenchulus reniformis
}

\author{
Yonathan Tilahun*
}

Center for Molecular Biology, Alabama A\&M University, Normal AL, 35762, USA

\author{
*Corresponding author: ytilahun@langston.edu
}

\begin{abstract}
Plant-nematode interactions have been studied extensively. The identification of genes expressed in root organs subsequent to nematode infection have been studied to a lower extent. Fewer still, potential resistance genes have been identified in cotton towards Rotylenchulus reniformis the reniform nematode (RN). Currently, there have been three cotton genomes completely sequenced. Gossypium, or cotton, genomes sequenced include: Gossypium hirsutum cv TM1, Gossypium arboreum, and Gossypium raimondii. This study imparts knowledge of differentially expressed genes (DEGs) after individual domesticated and wild cotton plants have been infected with approximately 50,000 juvenile RNs. After extraction of Total RNA from infected roots and subsequent next generation 454 pyrosequencing methods were employed, FastQC quality control measures were completed prior to Trimomatic-0.32 trimming from 33,788 reads, resulting in a significant decrease in the number of input reads (3454 input reads or DEGs). Putative descriptions were made for 634 input reads or DEGs, many of which were repeated multiple times as predicted proteins/enzymes or partials. The definition of 52 DEGs were made and enriched through the assignment of gene ontology (GO) terms that highlight categories of host plant genes for potential targets in future downstream transformation of cotton plants, especially those involved in strengthening systemic acquired resistance (SAR) or the hypersensitive response (HR) that occurs most often in plants when in defense against pathogen attack. This study reveals known protein/enzymes (52), unknown protein/enzymes (582) and unassigned DEGs (2820)
\end{abstract}

Keywords: Gossypium hirsutum cv.1218; Gossypium hirsutum cv. Coker; Gossypium arboreum; Gossypium barbadense; Rotylenchulus reniformis; cotton; reniform nematode; host-pathogen interaction; functional genomics; root transcriptome.

Abbreviations: GH1218_G. hirsutum cv.-1218; GHCoker_G. hirsutum cv. - Coker; GA_G. arboreum A2 87; GB_G. barbadense 713; cDNA_complementary Dioxyribonucleic acid; RN_reniform nematode; RNA_ribonucleic acid; TDFs_ Transcript derived fragments; DEGs_Differentially expressed genes; BLAST_Basic Local Alignment Search Tool; B2GO_BLAST 2 Gene Ontology; EST_Expressed Sequence Tags; rRNA_ribosomal RNA; NBS_nucleotide binding site; SMART_Switching Mechanism At 5' end of RNA Transcript; LD_Long distance; TAIR_The Arabidopsis Information Resource.

\section{Introduction}

Yield losses due to reniform nematode (RN, Rotylenchulus reniformis) make it the most damaging nematode pest of Gossypium hirsutum (Upland cotton) in the southeastern United States (Moore and Lawrence, 2012). Greater damage has been reported in the eastern half of the US cotton belt (Lawrence and McLean, 2001; Starr et al., 2005). Infestation by this pest has resulted in annual losses of approximately $\$ 130 \mathrm{M}$, with major impact in the states of Mississippi, Louisiana, and Alabama. Identification and integration of genetic resistance in cotton to $\mathrm{RN}$ is a more sustainable strategy but has not been fully attained in spite of recent exhaustive exploration ( $\mathrm{Li}$ et al., 2015) and more work in diverse cotton cultivars is needed. This will result in more efficient marker-systems that will likely aid in development and release of nematode-resistant cotton cultivars with superior yield potential and high fiber quality. Thus far, commercial cultivars of cotton are susceptible to RNs (Usery et al., 2005; and Weaver et al., 2007; Sacks and Robinson, 2009). The young meristematic elongation zone of young tap and secondary roots are especially vulnerable areas of attack by RN. Genes that are expressed after nematode attack have been studied in several species in paired resistant/susceptible hosts. The de novo assembly of cotton transcriptome collected during the early stages of RN infection, (15 days post inoculation) was carried out. In this study, the formation of syncytia in cotton roots caused a reaction from the plant hosts. Urwin et al. (2000) identified that certain proteinase inhibitor genes impart resistance to reniform nematode, but such genes in cultivated and wild relatives of cotton have not yet been identified. Efforts continue to identify sources of resistance to RN in Gossypium (Muhammad and Jones, 1990; Robinson et al., 2004) and previously assumed resistant or tolerant germplasm stocks have been released (Nelson, 2009; Jones et al., 1988; Cook et al., 1997a; Cook et al., 1997b). However, the only known completely tolerant species is $G$. longicalyx. Other possible strategies have been made to introgress resistance genes of diploid species, such as Gossypium arboreum, into cultivated tetraploid cotton (Bell and Robinson, 2004; Robinson et al., 2004; Avila et al., 2003; Agudelo et al., 2005; Robinson et. al., 2007; Dighe et al., 2001). Among these, two genotypes of Upland cotton have been identified with useful levels of resistance to RN, 
the $\mathrm{BC}_{7}$ linesLONREN-1 and -2 (Robinson et al, 2007). Additionally, G. barbadense, have also been an exception with some accessions having the ability to suppress RN populations by $70-90 \%$ (Robinson et al., 2004; Starr et al., 2007). The leading cultivars of cotton, with no known resistance to $\mathrm{RN}$, account for $90 \%$ of the world's annual cotton crop, underscoring the need for intensive exploration of genes. Through differentially expressed genes (DEGs) and comparison of tolerant versus susceptible species a valid approach for identification of genes, expressed transcripts or markers that play a key role in imparting tolerance are possible (Avila et al., 2003; Robinson et al., 2007).

The genomes of three species have been sequenced (Gossypium hirsutum cv TM1 (Udall et al., 2006; Chen et al., 2007; Li et. al., 2015); Gossypium arboreum (Li et. al., 2014); and Gossypium raimondii (Wang et. al., 2012). The information provided by the sequenced genomes aids in cotton trait improvement, but the nature of genes that regulate resistance to $\mathrm{RN}$ remains elusive. This study aims to identify the existing variation using DEG profiles of four genotypes. They represent three cotton species ( $G$. hirsutum, $G$. arboreum, and $G$. barbadense) and two genotypes from the same species ( $G$. hirsutum ) associated with RN infection. The goals were to: (1) Identify DEGs associated with the root transcriptome in cotton during early stages of infection; and 2) Determine DEGs that are shared among susceptible cultivars G. hirsutum (G. hirsutum cv. 1218 (GH1218), G. hirsutum $c v$. Coker (GHCoker)), while also identifying DEGs in comparison to the relatively more tolerant genotypes of $G$. arboreum cv. - A2 87 (GA) and G. barbadense cv. - GB713 (GB) to RN infection.

\section{Results}

\section{Differentially expressed genes (DEGs) after 15 days of $R N$ infection}

Approximately 9.5 Mbs of raw sequences were generated for four cDNA libraries. This study investigated DEGs with a length of 30 nucleotides (nt) and higher of GH1218, GHCoker, GA, and GB (Table 1). Collectively this study identified 33,788 DEGs after quality control using FasQC of 33,798 DEG input reads. The application of Trimmomatic0.32 trimmed adaptor and poor quality sub-sequences from the reads eliminated 30,334 (Tables 1 and Table 2). The remaining sequences of 3,454 DEGs across all four libraries were isolated and used for further analysis. Trimmomatic0.32 (Bolger et al., 2014) provided the resulting numbers for GH1218 (662), GHCoker (752), GA (1034), and for GB (1006) (Table 1 and Table 2). The percentage of GH1218 that had BLAST hits equaled 39\% (261/662), 11\% (80/752) for GHCoker, 14\% (149/1034) for GA and 10\% (98/1006) for GB. The identified functional classifications for each library were assigned for the known genes obtained through the use of BLAST in the application Blast2GO Pro (B2G) (Conesa et al., 2005; Conesa and Götz, 2008; Götz et al., 2008; and Götz et al., 2011). There were a total of 582 individual DEG descriptions that were identified as having putative homology to known sequences for protein/enzymes using B2G (Supplementary Table 1). Finally, 52 annotation descriptions were identified and the specific DEGs belonging to each genotype were defined as annotated gene ontology (GO) terms using B2G (Supplementary Table 1). The numbers of DEGs that did not share homology $(2,820)$ were not considered for further analysis (Table 2). There were 261 DEGs identified by BLAST and map hits as putative genes for GH1218 that revealed 6 individual descriptions for proteins/enzymes. GHCoker had 12 individual descriptions of proteins/enzymes with a total of 92 DEGs with BLAST and map hits. Sixteen individual descriptions were revealed for proteins/enzymes from a total of 165 DEGs that were derived from GA BLAST and map hits. The following are all shown in Table 2: 1) there were 98 DEGs with BLAST and map hits for GB that revealed 18 individual descriptions for proteins/enzymes; 2) four hundred-one DEGs were undefined by functional annotations for GH1218 in this study; six hundred sixty DEGs were undefined by functional annotation for GHCoker; eight hundred sixty-nine DEGs remained undefined by functional annotation for the GA cDNA library; finally, 890 DEGs were undefined functional annotations of GB (Table 2). The functions of the GH1218, GHCoker, GA, and GB TDFs revealed that the DEGs segregated to several categories. Response to stress was the most common function identified in all but the susceptible type GH1218 genotype after annotation. A comparison between Susceptible and Tolerant libraries, indicate that there are numerous target regions of DEGs that are associated with differences in response to stress induced by reniform nematode infection. Although the number of BLAST and map hits are similar for the DEGs associated with the Susceptible libraries (GH1218 and GHCoker), when compared to Tolerant (GA and GB), twice the number of segregation occurred for Tolerant DEGs than Susceptible in annotation. The comparison of DEGs in this study was conducted following the completion of the Gossypium hirsutum (Chen et al., 2007; Li et. Al, 2015), Gossypium arboreum (Li et. al., 2014), and Gossypium raimondii (Wang et. Al., 2012) genomes, therefore, they were among the references to reveal gene homology.

In summary, this study undertook comparative analysis of cotton-nematode interaction between $\mathrm{RN}$ infection of GH1218, GHCoker, GB, and GA. It characterized the root transcriptome and the DEG pattern among four genotypes of cotton. GO analysis identified gene ontology terms that are in the set of genes expressed from membranes and the plasma membranes, and responses to water and stress. Thus, asking the question, what is the role that the infection by reniform nematode plays during the expression of these genes?

\section{Discussion}

Nematode infection induces wounding, especially during establishment of an appropriate feeding site. Gene expression changes have been documented with wound or defense responses (Gheyson and Fenoll, 2002; Williamson and Kumar, 2006). These responses are present in both compatible (Susceptible) and incompatible (Tolerant) reactions. Supplementary Table 1 reflects a good depiction of what may be occurring. Therefore, a possible explanation will be made utilizing the DEGs depicted in Supplementary Table 1. Response to stresses including water stress is highlighted in each but one of the genotypes under the GO Names list. This seems to indicate that all the species have the molecular signaling system that identifies stress, whether biotic or abiotic. Further analysis identifies that the susceptible genotypes (GH1218 and GHCoker) share the GO Names list identifiers of "mitochondrion" and "integral component of membrane." The "integral component of membrane" is also identified for both Tolerant (GA and GB) genotypes. Integral components may be any number of numerous protein complexes that are imbedded partially or completely in the cellular membranes of the cells composing the root tissue of plants. Hydrolase activity was identified for the Susceptible GH1218 library (Supplementary Table 1). Hydrolase activity is known to be associated with diverse 
Table 1. Number of input reads, average length after trim, and number of reads after Trimmomatic-0.32.

\begin{tabular}{|c|c|c|c|c|c|c|}
\hline Library & $\begin{array}{c}\text { Number of } \\
\text { DEG input } \\
\text { reads }\end{array}$ & $\begin{array}{l}\text { Average } \\
\text { length (nt) }\end{array}$ & $\begin{array}{c}\text { Sequences after } \\
\text { FastQC }\end{array}$ & $\%$ Trimmed & $\begin{array}{l}\text { Avg. length } \\
\text { after trim }\end{array}$ & $\begin{array}{c}\text { Number of DEGs } \\
\text { after Trimmomatic - } \\
0.32 \\
\end{array}$ \\
\hline GH1218 & 6,091 & 181.5 & 6,087 & 99.93 & 164.3 & 662 \\
\hline GHCoker & 10,903 & 174.1 & 10,899 & 99.96 & 159.4 & 752 \\
\hline GA & 8,815 & 166.0 & 8,813 & 99.98 & 150.3 & 1034 \\
\hline GB & 7,989 & 160.3 & 7,989 & 100 & 144.7 & 1006 \\
\hline Total & 33,798 & & 33,788 & & & 3454 \\
\hline
\end{tabular}

Table 2. Total number of input reads, differentially expressed genes (DEGs) with BLAST hits, BLASTed without hits, and Blast2Gene Ontology (B2G) annotated DEGs.

\begin{tabular}{lcccc}
\hline Library & $\begin{array}{c}\text { Number of DEG Input } \\
\text { Reads }\end{array}$ & $\begin{array}{c}\text { DEGs with BLAST hits } \\
\text { of unknown } \\
\text { protein/enzymes }\end{array}$ & $\begin{array}{c}\text { B2G annotated } \\
\text { DEGs of known proteins/ } \\
\text { enzymes }\end{array}$ & $\begin{array}{c}\text { BLASTed } \\
\text { without hits }\end{array}$ \\
\hline GH1218 & 662 & 255 & 6 & 401 \\
GHCoker & 752 & 80 & 12 & 660 \\
GA & 1034 & 149 & 16 & 869 \\
GB & 1006 & 98 & 18 & 890 \\
Total & 3454 & 582 & 52 & 2820 \\
\hline
\end{tabular}

processes and mechanisms of plant defense, starch metabolism and cell wall remodeling against pathogen attack (Garcia-Garrido et al., 2005; Grienenberger et al., 2010; Tyler et al., 2010). UDP-glucosyltransferase activity was also identified, in this case the Susceptible GHCoker library (Supplementary Table 1). UDP-glucosyltransferase activity is known as a plant enzyme that typically is used by cells in the transfer of reactions involving biotic or abiotic stress and defense responses in addition to xenobiotics such as herbicides ( $\mathrm{Li}$ et al., 2001; Liu et al., 2015). The next components under the GO name list is mainly located in roots rather than in leaves, the inosine catabolic processes (Deng and Ashihara, 2010). Inosine is usually found in RNA and is included among degradation products that can be recycled for nucleotide synthesis. Plant ATP binding cassette (ABC) transporters move various substrates, using energy obtained by ATP hydrolysis, and are involved in several physiological functions, including detoxification of xenobiotics in addition to transport of hormones and secondary metabolites (Verrier et al., 2008; Yazaki et al., 2009; Kang et al., 2011; Shoji, 2014; Shitan et al., 2015). They tend to also accumulate in high concentrations in root tissue (Shitan et al., 2015) compared to leaf or stem tissue. The DEG annotations GO name F: protein serine/threonine kinase activity refers to a receptor that interacts with other proteins. Wide ranges of processes are affected, including disease resistance to develop self- versus non-self-recognition (Goring and Walker, 2004; Afzal et al., 2008). Protein phosphorylation is among the GO names list that was revealed in a GHCoker (Supplementary Table 1). Mitogenactivated protein kinases (MAPKs) are the main components of protein phosphorylation where a cascade of extracellular signals is transduced to respond to pathogen attack (Sidonskaya et al., 2015).

The response to biotic and/or abiotic stress, described thus far, is associated with signal transduction or transport of reactions. The question; however, is what determines tolerance or host resistance? Although a comprehensive conclusion cannot be drawn from this study, the proposal is that the difference between susceptibility and tolerance/resistance is based on the ability of the cells of the plant to mount a reaction that results in programmed cell death (PCD). The difference that is observed between GH1218, GHCoker, GA, and GB could be the inability for GH1218 and GHCoker to mount a defense by the activation of PCD as effectively as GA and GB. How do GA and GB cause this to happen? It may be the activation of GA defense through elevating levels of heavy metals that increase generation of reactive oxygen species (ROS), such as superoxide free radicals $\left(\mathrm{O}_{2}{ }^{-}\right)$, hydroxyl free radicals $\left(\mathrm{OH}^{*}\right)$, or non-free radical species such as singlet oxygen $\left(\mathrm{O}_{2}{ }^{*}\right)$ and hydrogen peroxide $\left(\mathrm{H}_{2} \mathrm{O}_{2}\right)$, in addition to cytotoxic compounds like methylglyoxal (MG). All of these cause oxidative stress by disturbing homeostasis through the disruption of pro- and anti-oxidants presence within the plant cells (Zengin and Munzuroglu, 2005; Hossain et al., 2012; Sytar et al., 2013; Emamverdian et al., 2015). Thus causing multiple deteriorative disorders among others; such as oxidation of protein and lipids, ion leakage, oxidative DNA attack, redox imbalance, and denature of cell structure and membrane. Ultimately, according to GA annotations the presence of metal ion binding results in the activation of programmed cell death (PCD) pathways (Rellán-Álvarez et al., 2006; Flora et al., 2008; Hatata and Abdel-Aal, 2008; Nagajyoti et al., 2010; Rascio and Navari-Izzo, 2011; Sharma et al., 2012). The defensive methods that GB uses are most likely similar to GA, in quicker detection, response, and in the mounting of defense through the PCD pathway similar to the use of the methods just discussed in addition to nucleic acid-binding proteins that positively and quantitatively regulate cotton resistance to reniform nematode (Deng et al., 2015).

\section{Materials and Methods}

\section{Plant materials}

\section{Greenhouse bioassay}

Genotypes were selected based on published reports of tolerance and susceptibility to $\mathrm{RN}$ and include tolerant species GA and GB (Udall et al., 2006); and two susceptible cultivars of GH1218 and GHCoker (GRIN: http://www.arsgrin.gov/). Seeds were germinated on moist germination paper in two days, and transplanted one per $150 \mathrm{~cm}^{3}$ Conetainer $^{\circledR}$ (Stuewe \& Sons, Tangent, Oregon, USA) in autoclaved 1:1 clay:sand mixture. Six replicates were arranged randomly in a greenhouse with $14 \mathrm{~h}$ of light daylight and temperature maintained at $30^{\circ} \mathrm{C}$ at the Plant Science Research Center at Auburn University (Auburn, AL). Cultures of RN were procured by collecting samples of soil from various infested field locations throughout Alabama. 
RN populations were increased in soil in greenhouse pot cultures with the host Gossypium hirsutum cotton cultivar PM 1218 BR. Sixty days later nematodes were extracted from the soil by combined gravity screening and sucrose centrifugal floatation (Jenkins, 1964). Each Conetainer ${ }^{\circledR}$ containing individual experimental susceptible or tolerant cotton plant was infected $10 \mathrm{~d}$ after transplanting with approximately 50,000 vermiform RN and additional reniform eggs present in the collected solution ( 2000-3000 eggs), by injecting the nematode suspension with a $1 \mathrm{ml}$ pipette near the base of the plant. The root transcriptome of treated cotton were characterized to determine DEGs. Four cDNA libraries were constructed from root tissues 15 days post inoculation (DPI) with 50,000 vermiform reniform nematodes per plant) for GH1218, GHCoker, GA, and GB. Test plants to confirm presence of female reniform nematodes with active syncytia were included in addition to the six replicates were also infected in similar fashion. On 15 DPI test plants were observed using a stereo-microscope after staining with acetocarmine. On 15 DPI roots were removed, washed with tap water immediately, flash-frozen in liquid nitrogen, placed in $50 \mathrm{ml}$ conical tubes, and stored at $-80^{\circ} \mathrm{C}$.

\section{Total RNA extraction for infected and non-infected plants}

Total RNA was isolated from root tissue ( $3 \mathrm{~g} \mathrm{GH} 1218,2 \mathrm{~g}$ GHCoker, $1 \mathrm{~g} \mathrm{GA}$, and $2 \mathrm{~g} \mathrm{~GB}$ ) using a modified protocol (Wan and Wilkins, 1994). The quality and concentration of the RNA was assessed using Experion ${ }^{\mathrm{TM}}$ RNA StdSens Analysis Kit (Bio-Rad, Hercules, CA, USA) using a $12 \mathrm{~K}$ DNA chip and Nanodrop 100 Spectrophotometer (NanoDrop, Wilmington, DE, USA). Electrophoresis of RNA extracted from $\mathrm{RN}$-treated root tissue of each cotton genotype was conducted on the Expirion ${ }^{\mathrm{TM}}$ (Bio-Rad Laboratories, Inc., Hercules, CA) electrophoresis unit, quality being assessed by both band and peak appearance. The resulting concentrations of total RNA obtained were: GH1218 (15.36 $\mathrm{ng} / \mu \mathrm{l})$, GHCoker (16.45 ng/ $\mu \mathrm{l})$, GA (13.35 ng/ $\mu \mathrm{l})$, and GB (15.18 $\mathrm{ng} / \mu \mathrm{l})$. Total RNA of the RN infected roots of GHCoker, GA, and GB were utilized to construct cDNA libraries using a $\mathrm{SMART}^{\mathrm{TM}}$ cDNA Library Construction kit (Clonetech, Mountain View, CA, USA) according to manufacturer protocol (www.clontech.com). These cDNA libraries were initially evaluated for their quality by gel electrophoresis. Similarly, they were also screened for their efficiency by isolating cDNA fragments from gel electrophoresis (QIAquickGel Extraction kit, Qiagen, Valencia, CA), followed by cloning (TOPO TA cloning kit, Invitrogen, Carlsbad, CA) and plasmid isolation (QIAquick Miniprep isolation Kit, Qiagen,Valencia, CA) and by sequencing methods using an ABI 3100 sequencer (Applied Biosystems, Foster City, CA). Sequence information derived from the screened samples reinforced the quality of the methods used through the identification of homologous sequences matching Gossypium hirsutum, Gossypium arboreum, and Gossypium barbadense verified by BLASTN analysis at the National Center for Biotechnology Information (NCBI:http://www. ncbi.nlm.nih.gov).

\section{cDNA Library preparation for 454 pyrosequencing and Transcriptome sequencing}

A cDNA library was prepared at concentrations of $7.5 \mu \mathrm{g}$ in a $210 \mu \mathrm{L}$ volume for $\mathrm{GH} 1218,5.2 \mu \mathrm{g}$ in $201 \mu \mathrm{L}$ volume for GHCoker, $4.4 \mu \mathrm{g}$ in a $190 \mu \mathrm{L}$ volume for GA, and $3.4 \mu \mathrm{g}$ in a $281 \mu \mathrm{L}$ volume for GB. Libraries were amplified with Long Distance PCR (LD PCR1 and LD PCR2) in order to achieve high yields of cDNA $(4-5 \mu \mathrm{g})$. Amplified samples were purified using GenElute ${ }^{\mathrm{TM}}$ PCR Clean-Up kit (SIGMAALDRICH, St. Louis, MO) and electrophoresed on a $1 \%$ agarose gel to ensure that appropriate fragment size ranges were obtained. Concentrations of the cDNA libraries were assessed using a Nanodrop spectrophotometer. The final cDNA libraries were sent to the Advanced Center for Genomic Technologies (ACGT) at the University of Oklahoma (Norman, OK) for sequencing using a 454/Roche Genome Sequencer FLX (GS20 FLX) instrument (454 Life Sciences, Branford,CT). Over $9.5 \mathrm{Mb}$ of raw sequence data was generated from the four cDNA libraries: GH1218, GHCoker, GA, and GB. Samples were analyzed at The Advanced Center for Genome Technology (ACGT) at the University of Oklahoma (Norman, OK) using Newbler (454 Life Sciences, Branford, CT), software that accompanied the 454 pyrosequencing instrument. Read quality was assessed further with FastQC (Andrews, 2010), followed by adaptor trimming with Trimmomatic-0.32 (Bolger et al., 2014).

\section{Sequence assembly and data analysis}

The flowgrams generated by a 454 GS 20 FLX instrument were read and produced raw reads using Newbler (454 Life Sciences, Branford, CT). Raw sequence data were quality controlled using FastQC and trimmed using Trimmomatic0.32 for the following sequences: >Key_plus_tag TCAGACGAGTGCGT; >SMART_IV AAGCAGTGGTATCAACGCAGAGTGGCCATTACG GCCGGG; $>$ CDS_III ATTCTAGAGGCCGAGGCGGCCGACATGTTTTTTTTTTTTTT; >5prime_PCR_Primer AAGCAGTGGTATCAACGCAGAGT; and >5prime_PCR_Primer_ fragment AAGCAGTGGTAT. As these were initially sequences formatted as .fna and .qual or .sff, they were converted to fastq formats through utilizing bioinformatics conversion software suites on iPlant Discovery Environment (Goff et al., 2011).

The identified putative functional classifications for each library were assigned for the known genes obtained through the use of BLAST in the application Blast2GO Pro (B2G) (Conesa et al., 2005; Conesa and Götz, 2008; Götz et al., 2008; and Götz et al., 2011). The reference genome sequence for all sample sequences was Gossypium hirsutum. Blast2GO was then utilized to identify putative and functional classifications of the homologous sequences. Blast2GO was further utilized for subtraction hybridization to identify unique sequences from each sample genotypic data.

The cDNA libraries were constructed from the RN infected root tissues, Therefore it is understood that $\mathrm{RN}$ associated sequences are likely integral to the raw data. Further excision of RN associate sequences indicated that pathogen DEGs existed among the cDNA libraries.

\section{Conclusion}

This study examined four cotton genotypes, 15 DPI, providing insight into cotton-reniform interactions. Comprehensive gene expression profiles of syncytial development significantly will advance our understanding of plant resistance to RN. This study provides many possible targets for full-length cDNA marker development for molecular based RN resistance strategies in cotton utilizing natural mechanisms of resistance. The mechanism of plant response to $\mathrm{RN}$ has practical significance for nematode control through the development of future resistant crop varieties. Also, this work provides a useful resource for the cotton research community by providing a DEG repository 
for further investigations. The defined DEGs can be used to strengthen additional downstream studies by providing iterative genes that may be utilized for transformation of plants. Furthermore, as more defined functions become apparent, the data accumulated in this study will strengthen the breadth of applications that will be made towards combating $\mathrm{RN}$ in cotton.

\section{Acknowledgements}

Acknowledgements go to the USDA-CSREES (2004-3881415160, ALAX 011-206, ALAX 011-706), NSF Grant: 0703470, USDOEd - Title III - HBGI for providing financial support, and Auburn University, Langston University, and Alabama A\&M University for providing the property, and nurturing environment for such research to be completed.

\section{References}

Afzal AJ, Wood AJ, Lightfoot DA (2008) Plant receptorlike serine threonine kinases: roles in signaling and plant defense. Molecular Plant-Microbe Interact. 21(5): 507517.

Agudelo P, Robbins RT, Stewart JMcD., Bell A, Robinson A F (2005) Histological observations of Rotylenchulus reniformis on Gossypium longicalyx and interspecific cotton hybrids. J Nematol. 37(4): 444-447.

Andrews S (2010) FastQC:a quality control tool for high throughput sequence data. Available online at:http://www.bioinformatics.babrahana.ac.uk/prokects/f astqc.

Avila CA, Stewart JMcD, Robbins RT (2003) Transfer of reniform nematode resistance from diploid cotton species to tetraploid cultivated cotton. Summaries of Arkansas Cotton Research. 521:183-186.

Bell AA and Robinson AF (2004) Development and characteristics of triple species hybrids used to transfer reniform nematode resistance from Gossypium longicalyx to Gossypium hirsutum. In: Proceedings of the Beltwide Cotton Conferences, January 5-9, 2004, San Antonio, Texas. p 422.

Bolger AM, Lohse M, Usadel B (2014) Trimmomatic: A flexible trimmer for illumina sequence data. Bioinformatics. 30(15): 2114-2120.

Chen ZJ, Scheffler BE, Dennis E, Triplett BA, Zhang T, Guo W, Chen X, Stelly DM, Rabinowicz PD, Town CD, Arioli T, Brubaker C, Cantrell RG, Lacape J-M, Ulloa M, Chee P, Gingle AR, Haigler CH, Percy R, Saha S, Wilkins T, Wright R, Deynze AV, Zhu Y, Yu S, Abdurakhmonov I, Katageri I, Kumar PA, ur-Rahman M, Zafar Y, Yu JZ, Kohel RJ, Wendel JF, Paterson AH (2007) Toward sequencing cotton (Gossypium) genomes. Plant Physiology. 145:1303-1310.

Conesa A, Götz S, Garcia-Gomez JM, Terol J, Talon M, Robles M (2005) Blast2GO: a universal tool for annotation, visualization, and analysis in functional genomics research. Bioinformatics. 21: 3674-3676.

Conesa A, Götz S (2008) Blast2GO: A comprehensive suite for functional analysis in plant genomics. Int $\mathbf{J}$ Plant Genomics. 2008: 1-13.

Cook CG, Robinson AF, Namken LN (1997a) Tolerance to Rotylenchulus reniformis and resistance to Meloidogyne incognita race 3 in high-yielding breeding lines of Upland cotton. J Nemato. 29: 322-328.
Cook CG, Namken LN, Robinson AF (1997b) Registraion of N220-1-91, N222-1-91, N320-2-91, and N419-1-91 nematode-resistant cotton germplasm lines. Crop Sci. 37: 1029-1029.

Deng WW, Ashihara H (2010) Profiles of purine metabolism in leaves and roots of Camillia sinensis seedlings. Plant Cell Physiol. 51(12): 2105-2118.

Deng H, Liu H, Li X, Xiao J, Wang S (2015) A CCCHtype zinc finger nucleic acid-binding protein quantitatively confers resistance against rice bacterial blight disease. Plant Physiol. 158: 876-889.

Dighe N, Stewart JM, Robbins RT (2001) Hybridization of exotic germplasm with Upland cotton as the first step in transfer of reniform nematode resistance. Summaries of Arkansas Cotton Research. 497: 92-95.

Emamverdian A, Ding Y, Mokhberdoran F, Xie Y (2015) Heavy metal stress and some mechanisms of plant defense response. Sci World J. 2015(756120): 1-18.

Flora SJS, Mittal M, Mehta A (2008) Heavy metal induced oxidative stress \& its possible reversal by chelation therapy. Ind J Medic Res. 128(4): 501-523.

Garcia-Garrido JM, Ocapo JA, Garcia-Romera I (2002) Enzymes in the arbascular mycorrhizal symbiosis, In: R. G. Burns and R. P. Dick (eds) Enzymes in the environment: activity, ecology, and applications. New York, pgs. 125-151.

Gheysen G, Fenoll C (2002) Gene expression in nematode feeding sites. Annu Rev Phytopathol. 40: 191-219.

Götz SJM, García-Gómez J, Terol TD, Williams SH Nagaraj, Nueda MJ, Robles M, Talón M, Dopazo J., Conesa A (2008) High-throughput functional annotation and data mining with the Blast2GO suite. Nucleic Acids Res. 36: 3420-3435.

Götz SR, Arnold P, Sebastián-León S, Martín-Rodríguez P, Tischler MA, Jehl J, Dopazo T, Conesa A (2011) B2G-FAR, a species centered GO annotation repository. Bioinformatics. 27(7): 919-924.

Goff SA, Vaughn M, McKay S, Lyons E, Stapleton AE, Gessler D et al. (2011) The iPlant Collaborative: Cyberinfrastructure for plant biology. Front Plant Sci. 2: 1-34.

Goring DR, Walker JC (2004) Plant sciences: self rejection, a new kinase connection. Science. 303: 14741475 .

Grienenberger E, Geoffroy P, Mutterer J, Legrand M, Heitz T (2010) The interplay of lipid acyl hydrolases in inducible plant defense. Plant Signal Behav. 5(10): 1181-1186.

Hatata MM, Abdel-Aal EA (2008) Oxidative stress and antioxidant defense mechanisms in response to cadmium treatments. Amer-Eurasian J Agric Environment Sci. 4(6): 655-669.

Hossain MA, Piyatida P, da Silva JAT, Fujita M (2012) Molecular mechanism of heavy metal toxicity and tolerance in plants:central role of glutathione in detoxification of reactive oxygen species and methylglyoxal and in heavy metal chelation. J Bot. 2012(872875): 1-37.

Jenkins WR (1964) A rapid centrifugal flotation technique for separating nematodes from soil. Plant Dis Res. 48: $\mathrm{p}$ 692. 
Jones JE, Beaseley JP, Dickson JI, Caldwell WD (1988) Registration of four cotton germplasm lines with resistance to reniform and root-knot nematodes. Crop Sci. 28: 199-200.

Kang J, Park J, Choi H, Burla B, Kretzschmar T, Lee Y, Martinoia E (2011) Plant ABC transporters. The Arabidopsis Book. e0153: 1-25.

Li F, Fan G, Wang K, Sun F, Yan Y, Song G, Li Q, Ma Z, Lu C, Zou C, Chen W, Liang X, Shang H, Liu W, Shi C, Xiao G, Gou C, Ye W, Xu X, Zhang X, Wei H, Li Z, Zhang G, Wang J, Liu K (2014) Genome sequence of the cultivated cotton Gossypium arboreum. Nat Genetics. 46: 567-572.

Lawrence GW, McLean KS (2001) Reniform nematodes. In T.L. Kirkpatrick and C.S. Rothrock (eds) Compendium of cotton diseases, second edition. APS Press, St. Paul, MN. pgs. 42-44.

Li F, Fan G, Lu C, Xiao G, Zou C, Kohel RJ, Ma Z, Shang H, Ma X, et al. (2015) Genome sequence of cultivated Upland cotton (Gossypium hirsutum TM-1) provides insights into genome evolution. Nat Genetics. 33: $524-530$

Li Y, Baldauf S, Lim E-K, Bowels DJ (2001) Phylogenetic analysis of the UDP-glycosylatransferase multigene family of Arabidopsis thaliana. J Biolo Chem. 276(6): 4338-4343.

Liu Z, Yan J-P, Li D-K, Luo Q, Yan Q, Liu Z-B, Ye L-M, Wang JM, Li XF, Yang Y (2015) UDPGlucosyltransferase71C5, a major Glucosyltransferase, mediates abscisic acid homeostasis in Arabidopsis. Plant Physiol. 167(4): 1659-1670.

Moore SR, Lawrence KS (2012) Rotylenchulus reniformis in cotton: current methods of management and the future of site-specific management. Nematropica. 42(2): 227-236.

Muhammad N, Jones JE (1990) Genetics of resistance to reniform nematode in Upland cotton. Crop Sci. 30: 1316.

Nagajyoti PC, Lee KD, Sreekanth TVM (2010) Heavy metals, occurrence and toxicity for plants: a review. Environ Chem Letters. 8(3): 199-216.

Nelson TC and Walker M (2009) Trio Honored With 2008 Cotton Genetics Research Award. National Cotton Council of America. http://www.cotton.org/news/meetings/2009bw/cotgene.c fm.

Rellán-Álvarez RC, Ortega-Villasante A, ÁlvarezFernández FFD Campo, Hernández LE (2006) Stress responses of Zea mays to cadmium and mercury. Plant Soil. 279(1-2): 41-50.

Rascio N and Navari-Izzo F (2011) Heavy metal hyperaccumulating plants: how and why do they do it? And what makes them so interesting? Plant Sci. 180(2): 169-181.

Robinson AF, Bridges AC, Percival AAE (2004) New sources of resistance to the reniform (Rotylenchulus reniformis Linford and Oliveira) and root-knot (Meloidogyne incognita (Kofoid \& White) Chitwood) nematode in upland (Gossypium hirsutum L.) and sea island (G. barbadense L.) Cotton. J Cot Sci. 8: 191-197.

Robinson AF, Bell AA, Dighe ND, Menz MA, Nichols RL, Stelly DM (2007) Introgression of Resistance to Nematode Rotylenchulus reniformis into Upland Cotton
(Gossypium hirsutum) from Gossypium longicalyx. Crop Sci. 47: 1865-1877.

Sacks EJ, Robinson AF (2009) Introgression of resistance to reniform nematode (Rotylenchulus reniformis) into Upland cotton (Gossypium hirsutum) from Gossypium arboreum and a $G$. hirsutum/Gossypium aridum bridging line. Field Crops Res. 112(1): 1-6.

Sharma P, Jha AB, Dubey RS, Pessarakli M (2012) Reactive oxygen species, oxidative damage, and antioxidative defense mechanism in plants under stressful conditions. J Bot. 2012(217037): 1-26

Shitan N, Terasaka K, Yamamoto H, Sato F, Yazaki K (2015) Two B-type ATP-binding cassette (ABC) transporters localize to the plasma membrane in Thalictrum minus. Plant Biotechnol. 32: 243-247.

Shoji T (2014) ATP-binding cassette and multidrug and toxic compound extrusion transporters in plants: a common theme among diverse detoxification mechanisms. Int Rev Cell Mol Biol. 309: 303-346.

Sidonskaya E, Schweighofer A, Shubchynskyy V, Kammerhofer N, Hofmann J, Wieczorek K, Meskiene I (2016) Plant resistance against the parasitic nematode Heterodera schachtii is mediated by MPK3 and MPK6 kinases, which are controlled by the MAPK phosphatase AP2C1 in Arabidopsis. Journal of Experimental Botany. 67: $107-118$

Starr JL, Carneiro RG, Ruano O (2005) Nematode parasites of cotton and tropical fiber crops. In Plant Parasitic Nematodes in Subtropical and Tropical Agriculture, $2^{\text {nd }}$ Edition (ed) Luc M., R.A. Sikora, and J. Bridge. Wallingford, UK: CABI Publishing. pgs. 733750.

Starr JL, Koenning SR, Kirkpatrick TL, Robinson AF, Roberts PA, Nichols RL (2007) The future of nematode management in cotton. J Nematol. 39(4):283-294.

Sytar O, Kumar A, Latowski D, Kuczynska P, Strzalka K, M. Prasad NV (2013) Heavy metal-induced oxidative damage, defense reactions, and detoxification mechanisms in plants. Acta Physiologiae Planatarum. 35(4): 985-999.

Tyler L, Bragg JN, Wu J, Yang X, Tuskan GA, Vogel JP (2010) Annotation and comparative analysis of the glycoside hydrolase genes in Brackypodium distachyon. BMC Genomics. 11(600): 1-21.

Udall JA, Swanson JM, Haller K, Rapp RA, Sparks ME, Hatfield J, Yu Y, Wu Y, Dowd C, Arpat AB, et al. (2006) A global assembly of cotton ESTs. Genome Res. 16: 441-450.

Urwin PE, Levesley A, McPherson MJ, Atkinson HJ (2000) Transgenic resistance to the nematode Rotylenchulus reniformis conferred by Arabidopsis thaliana plants expressing proteinase inhibitors. Molecular Breeding. 6: 257-264.

Usery S, Lawrence K, Lawrence G, Burmester C (2005) Evaluation of cotton cultivars for resistance and tolerance to Rotylenchulus reniformis. Nematropica. 35(2): 121-133.

Verrier PJ, Bird D, Burla B, Dassa E, Forestier C, Geisler M, Klein M, Kolulisaoglu U, Lee Y, Martinoia E, Murphy A, Rea PA, Samuals L, Schultz B, Spalding EJ, Yazaki K, Theodoulou FL (2008) Plant ABC proteins: a unified nomenclature and updated inventory. Trends Plant Sci. 13: 151-159. 
Wan C-Y, Wilkins TA (1994) RNA isolation from Gossypium species. Anal Biochem. 223: 7-12.

Wang K, Wang Z, Li F, Ye W, Wang J, Song G, Yue Z, Cong L, Shang H, Zhu S, Zou C, Li Q, Yuan Y, Lu C, Wei H, Gou C, Zheng Z, Yin Y, Zhang X, Liu K, Wang B, Song C, Shi N, Kohel RJ, Percy RG, Yu JZ, Zhu YX, Wang J, Yu S (2012) The draft genome of a diploid cotton Gossypium raimondii. Nat Genetics. 44: 10981103.

Weaver DB, Lawrence KS, Santen E. van (2007) Reniform nematode resistance in Upland cotton germplasm. Crop Sci. 47(1): 19-24.

Williamson VM. Kumar A (2006) Nematode resistance in plants: the battle underground. Trends Genetics. 22(7): 396-403.
Yazaki K, Shitan N, Sugiyama A, Takanashi K (2009) Cell and molecular biology of ATP-binding cassete proteins in plants. Int Rev Cell Mole Biol. 276: 263-299. Zengin FK, Munzuroglu O (2005) Effects of some heavy metals on content of chlorophyll, proline, and some antioxidant chemicals in bean (Phaseolus vulgaris L.) seedlings. Acta Biologica Cracoviensia Series Botanica. 47(2): 157-164. 